
(2) 1 2 33

ms.22905

\title{
FoxO/Daf-16 Restored Thrashing Movement Reduced by Heat Stress
} in Caenorhabditis elegans

\author{
Tsubasa Furuhashi, Kazuichi Sakamoto
}

Graduate School of Life and Environmental Sciences, University of Tsukuba, 1-1-1 Tennoudai, Tsukuba, Ibaraki 305-8572, Japan

E-mail: sakamoto@biol.tsukuba.ac.jp

Running title: Daf-16 promotes heat tolerance in nematodes

ms. has 25 pages, 5 figures, 3 tables.

${ }^{\#}$ Corresponding author:

Dr. Kazuichi Sakamoto;

Graduate School of Life and Environmental Sciences, University of Tsukuba, 1-1-1 Tennoudai, Tsukuba, Ibaraki 305-8572, Japan Tel.: +81 29853 4676; Fax: +81 298534676

E-mail: sakamoto@biol.tsukuba.ac.jp

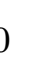




\begin{abstract}
Many studies on thermotolerance have been done in Caenorhabditis elegans in order to extend survival under heat stress; Daf-16, a homolog of FoxO in Caenorhabditis elegans, was detected as the key factor in thermotolerance. However, the recovery process from heat stress damage has been seldom discussed. In this study, we analyzed the roles of FoxO/Daf-16 on the recovery from heat stress damage by monitoring thrashing movement. Heat shock reduced the movement, which was restored by culturing at $20^{\circ} \mathrm{C}$. Thrashing movement was not restored in the daf-16 mutant, which suggests that Daf-16 is one of the essential factors in repairing the damage. Movement restoration was promoted in the daf-2 mutant, a homolog of Insulin/IGF-1-like receptor, in a daf-16-dependent manner. In addition, heat stress decreased the expression of daf-28 and ins-7, agonists of Daf-2. Taken together, these results revealed that FoxO/Daf-16 removes heat stress damage and restores movement via inhibition of the insulin-like signaling pathway in C. elegans, suggesting that FoxO/Daf-16 plays a critical role in thermotolerance.
\end{abstract}

Key words: Caenorhabditis elegans, Thermotolerance, Daf-16, Thrashing movement, Insulin-like signaling pathway

\title{
1. Introduction
}

Heat stress induces protein denaturation or aggregation (Kampinga, 1993) and $\mathrm{Ca}^{2+}$ leakage (Kourtis et al., 2012; Lanner et al., 2012); therefore, heat stress can hinder an organism's survival. In order to protect our own health, we need to understand how humans prevent the accumulation of and recover from heat stress damage; therefore, studies on thermotolerance are needed.

Many studies on thermotolerance have been performed in C. elegans. Thermotolerance in C. elegans is related to the insulin-like signaling pathway. C. elegans die quickly under heat stress; however, their survival can be extended by inducing a daf-2 (insulin/IGF receptor homolog) knock out (KO) (Lithgow et al., 1995). Because the daf-2 KO induces the nuclear localization of Daf-16, a homolog of FoxO, (Lin et al., 2001; Henderson and Johnson, 2001; Yen et al., 2011) and extends the lifespan of $C$. elegans in a Daf-16-dependent manner (Kenyon et al., 1993; Murphy et al., 2003; Yen et al., 2011), Daf-16 is considered a key factor in thermotolerance. In a previous study, 
it was shown that Daf-16 is localized by heat stress in nucleus (Henderson and Johnson, 2001; Lin et al., 2001; Singh and Aballay, 2009). It was proved that Daf-16 overexpression extends survival under heat stress (Henderson and Johnson, 2001). Our previous study showed that viability is decreased by the daf-16 $\mathrm{KO}$ under heat stress (Horikawa and Sakamoto, 2009). In addition, the survival extension by the daf-2 KO is dependent on Daf-16 under heat stress (McColl et al., 2010). Therefore, FoxO/Daf-16 is expected to prevent the accumulation of damage from heat stress.

Although many studies focused on FoxO/Daf-16 and thermotolerance, the recovery process from heat stress damage has been seldom discussed. Likely, C. elegans can restore the damage from heat stress, because it was suggested that the stimulation of weak heat stress extends lifespan and induces thermotolerance (Lithgow et al., 1995; McColl et al., 2010; Kourtis et al., 2012) and innate immunity in a Daf-16-dependent manner (Singh and Aballay, 2006). In addition, the daf-2 mutant survives for a long time compared to WT after acute heat shock, which is daf-16 dependent (McColl et al., 2010). Hence, we analyzed the mechanisms underlying the restoration from heat stress damage by using C. elegans.

For the recovery, we decided to use thrashing movement because $C$. elegans can be observed for a long time after heat treatment. The movement of $C$. elegans is often used as an index in studies of polyglutamine (PolyQ) diseases. C. elegans expressing PolyQ had a larger decline in movement or were paralyzed in an age- and temperature-dependent manner (Morley et al., 2002; van Ham et al., 2010; Haldimmann et al., 2011). Because heat stress induces protein aggregation (Kampinga 1993), it is probable that heat stress alters thrashing movement.

We studied the roles of Daf-16 on altered thrashing movement in C. elegans exposed to heat stress and analyzed the activation pathway of Daf-16 under heat stress. We discovered a novel function for Daf-16, which is the focus of much C. elegans research (Yen et al., 2011), such as longevity (Kenyon et al., 1993; Murphy et al., 2003; Hashimoto et al., 2010; Kwon et al., 2010), thermotolerance, oxidative stress (Honda and Honda, 1999; Heidler et al., 2010), lipid metabolism (Horikawa and Sakamoto, 2009; Horikawa and Sakamoto, 2010), and innate immunity (Singh and Aballay, 2006; Alper et al., 2007; Kawli and Tan, 2008; Hahm et al., 2011)

\section{Materials and methods}


103 Wild-type (WT) Caenorhabditis elegans Bristol $\mathrm{N}_{2}$, daf-16 mutant (mgDf-15), daf-2 104 mutant (e1370), and TJ356 (daf-16::gfp) transgenic mutants were provided by the 105 Caenorhabditis Genetics Center (CGC, MN, USA). Each strain was cultured on 106 nematode growth medium (NGM) agar plates seeded with E. coli OP50 as previously described (Brenner 1974).

\section{$2.2 \mathrm{NaClO}$ treatment}

To synchronize the growth of C. elegans, adult worms were treated with a 10:1 NaClO solution ( $\mathrm{NaClO}$ [Haiter, KAO, Tokyo, Japan]:10N NaOH [WAKO, Osaka, Japan)]). The eggs were cultured in S-basal $(0.1 \mathrm{M} \mathrm{NaCl}$ [Kanto Chemical, Tokyo, Japan], 50 $\mathrm{mM}$ potassium phosphate buffer [pH 6.0]) until hatching at $20^{\circ} \mathrm{C}$.

\subsection{Preparing $c D N A$}

Adult worms were collected by S-basal and washed with dDW to remove E. coli. RNA was extracted with RNAiso PLUS (Takara, Shiga, Japan) from C. elegans extract and treated with DNase I (Takara). cDNA was synthesized by using M-MLV Reverse Transcriptase (Takara) or PrimeScript ${ }^{\circledR}$ RT reagent Kit with gDNA Eraser (Perfect Real Time) (Takara).

\subsection{Feeding RNAi}

Plasmid DNA L4440 (Fire Laboratory), which has a daf-16 cDNA fragment in the multicloning site, was transformed into Escherichia coli HT115 treated with $50 \mathrm{mM}$ $\mathrm{CaCl}_{2}$ (WAKO). Primers for preparing the cDNA insert are listed in Table 1. The HT115 strain transformed with the L4440 plasmid was treated with isopropyl- $\beta$-D-thiogalactopyranoside (IPTG; WAKO) to induce dsRNA expression. After treatment, HT115 was seeded onto NGM RNAi medium plates (Timmons and Fire 1998). Age-synchronized L1 larvae were transferred onto an RNAi plate.

\subsection{Pharynx pumping assay under heat stress}

Age-synchronized L1 larvae were transferred onto a plate and cultured for 4 days at $20^{\circ} \mathrm{C}$. After 4 days, the $C$. elegans adult worms were transferred onto a new NGM plate seeded with OP50 and cultured at $35^{\circ} \mathrm{C}$ for $0-4 \mathrm{~h}$. Ten $C$. elegans were chosen randomly, and pharynx pumping was counted for $15 \mathrm{~s}$ every $\mathrm{h}$. 


\subsection{Thrashing movement assay under heat stress}

Age-synchronized L1 larvae were transferred onto a plate and cultured for 4 days at $20^{\circ} \mathrm{C}$. After 4 days, the C. elegans adult worms were transferred onto an NGM plate without food and cultured at $35^{\circ} \mathrm{C}$ for $4 \mathrm{~h}$. After heat treatment, the C. elegans were transferred onto a new plate and cultured for 0-24 h, after which 10 C. elegans chosen randomly were moved to S-basal on an NGM plate without food and the thrashing movement was counted for $15 \mathrm{~s}$. However, we did not choose worms that still showed remarkable weakness $3 \mathrm{~h}$ after heat treatment.

\subsection{Observation of Daf-16::GFP}

Age-synchronized TJ356 (daf-16::gfp) was collected by S-basal and fixed in 1\% paraformaldehyde (PFA) solution ((2\% PFA [WAKO], 20\% EtOH [WAKO], $25 \mathrm{mM}$ potassium phosphate buffer, $50 \mathrm{mM} \mathrm{NaCl}$ [Kanto Chemical]):S-basal = 1:1). GFP fluorescence was observed under a BZ8000 fluorescence microscope (KEYENCE Japan, Osaka, Japan).

\subsection{Analysis of gene expression}

C. elegans exposed to heat stress for $4 \mathrm{~h}$ were collected by S-basal. cDNA was prepared and amplified on an ABI-7300 system (Applied Biosystems, CA, USA) using Thunderbird SYBR qPCR Mix (TOYOBO, Osaka, Japan). Primers are listed in Table 1.

\subsection{Statistical analysis}

Significant differences were analyzed with t-test, Games-Howell test and Dunnett's T3 test with statistical differences represented by $* p<0.05$ and $* * p<0.005$.

\section{Results}

\subsection{C. elegans can restore the thrashing movement reduced by heat stress} First, we observed pharynx pumping under heat stress, because it was reported that feeding of C. elegans is totally inhibited at $32^{\circ} \mathrm{C}$ (Jones and Candido, 1999). As a result, pumping was remarkably decreased by heat stress (Figure 1A). Because starvation stress affects the insulin signaling pathway and the translocation of Daf-16 (Henderson and Johnson, 2001; Weinkove et al., 2006), we compared movement under heat stress 
170 conditions to normal conditions on an NGM plate without food to remove the quantity 171 of food ingested as a factor. We analyzed the altered thrashing movement under heat 172 stress. C. elegans adult worms were cultured at $20^{\circ} \mathrm{C}$ for $4 \mathrm{~h}\left(20^{\circ} \mathrm{C}\right.$, $\left.[+]\right)$, or cultured on 173 an NGM plate without food at $20^{\circ} \mathrm{C}\left(20^{\circ} \mathrm{C},[-]\right)$ or $35^{\circ} \mathrm{C}$ for $4 \mathrm{~h}\left(35^{\circ} \mathrm{C},[-]\right)$. After $4 \mathrm{~h}, C$.

174 elegans were transferred to a new NGM plate seeded with OP50 and cultured at $20^{\circ} \mathrm{C}$ 175 for 0-24 h. We found no change in movement between the NGM plate with food and 176 the E. coli-free plate; however, heat stress remarkably reduced the thrashing movement 177 (Figure 1B). After $24 \mathrm{~h}$, the movement of $C$. elegans under heat stress $\left(35^{\circ} \mathrm{C}\right.$, [-]) 178 increased by $80 \%$. Therefore, $C$. elegans can restore the thrashing movement reduced by 179 heat stress.

180

\subsection{Daf-16 is activated immediately after heat shock}

182 Next, we observed Daf-16 activation. First, we used the TJ356 strain (daf-16::gfp) to 183 observe the behavior of Daf-16 under heat stress. Adult TJ356 worms were cultured at $20^{\circ} \mathrm{C}$ for $4 \mathrm{~h}\left(20^{\circ} \mathrm{C},[+]\right)$, or cultured on an NGM plate without food at $20^{\circ} \mathrm{C}\left(20^{\circ} \mathrm{C},[+]\right)$ or $35^{\circ} \mathrm{C}$ for $4 \mathrm{~h}\left(35^{\circ} \mathrm{C}\right.$, [-]). As a result, Daf-16 was localized by heat stress in nuclear

186 (Figure 2A). Although, the previous study suggested that Daf-16 is localized in nuclear under starvation stress for 1 day in TJ356 (Bamps et al., 2009), starvation stress for $4 \mathrm{~h}$ 188 didn't induce Daf-16 nuclear translocation (Fig. 2A). Therefore, it is suggested that heat 189 stress induces Daf-16 nuclear translocation more than starvation stress. Heat-treated 190 TJ356 was transferred to a new NGM plate seeded with OP50 and cultured at $20^{\circ} \mathrm{C}$ for $24 \mathrm{~h}$. GFP localization of worms treated with heat stress $\left(35^{\circ} \mathrm{C}\right.$, [-] $)$ at $24 \mathrm{~h}$ was decreased compared to that of $0 \mathrm{~h}$ (Fig. 2A), as found in previous studies (Singh and Aballay, 2009). Even though, nuclear localization ratio of worms treated with heat stress $\left(35^{\circ} \mathrm{C}, 24 \mathrm{~h}\right)$ was still much higher than those of other conditions $\left(20^{\circ} \mathrm{C}, 24 \mathrm{~h}\right) . \mathrm{In}$ addition, we analyzed the expression of hsp-12.6, a daf-16 downstream gene, by using qRT-PCR. The results showed that heat stress increased hsp-12.6 expression (Figure 2B) as previously reported (Hsu et al., 2003; McColl et al., 2010). These results showed that the transcriptional activity of Daf-16 was enhanced immediately after heat treatment.

200

\subsection{Daf-16 is needed to restore thrashing movement reduced by heat stress} mutant (mgDf50). WT and daf-16 mutants were transferred to a new NGM plate and 
204 cultured at $20^{\circ} \mathrm{C}$ or $35^{\circ} \mathrm{C}$ for $4 \mathrm{~h}$. After $4 \mathrm{~h}$, each strain was transferred to a new NGM 205 plate seeded with OP50 and cultured at $20^{\circ} \mathrm{C}$ for 0,12 , and $24 \mathrm{~h}$. The movement of the 206 daf-16 mutant could not be restored (Table 2 and Figure 3A). We also observed the movement of daf-16 RNAi under heat stress. C. elegans treated with daf-16 RNAi also displayed restoration inhibition (Table 2 and Figure 3B). Additionally, daf-16 RNAi remarkably decreased the GFP fluorescence of the TJ356 strain (Figure 3C). Therefore, daf-16 was knocked down by our plasmid DNA. These results suggest that Daf-16 restores the thrashing movement reduced by heat stress.

\subsection{Daf-2 promotes restoration of thrashing movement in dependent of Daf-16}

214 To analyze altered movement under conditions of Daf-16 activation, we used a daf-2 mutant (e1370). WT or daf-2 mutants were transferred to a new NGM plate and cultured at $20^{\circ} \mathrm{C}$ or $35^{\circ} \mathrm{C}$ for $4 \mathrm{~h}$, after which each strain was transferred to a new NGM plate seeded with $\mathrm{OP} 50$ and cultured at $20^{\circ} \mathrm{C}$ for 0,3 , and $6 \mathrm{~h}$. As a result, the movement of the daf- 2 mutant was greater than the WT $0 \mathrm{~h}$ after heat treatment, and it was almost restored $6 \mathrm{~h}$ later (Table 3 and Figure 4A). Next, we treated the daf-2 mutant with daf-16 RNAi. The results showed that the movement of the daf- 2 mutant was unchanged between the empty vector and the daf- 16 RNAi at $0 \mathrm{~h}$. In addition, thrashing movement was not increased by daf-16 knockdown (Table 3 and Figure 4B). Previous study suggested heat stress increase hsp-12.6 expression in daf-2 mutant in a Daf-16 dependent manner (McColl et al., 2012). We analyzed the hsp-12.6 expression of WT and daf-2 mutant in recovery process. As a result, expression of hsp-12.6 in daf-2 mutant was still high compared to that of WT in recovery process (Fig. 4C). And, hsp-12.6 expression was reduced due to restoration of thrashing movement (Fig. 4A and Fig. 4C). Therefore, these results suggested that daf-2 $\mathrm{KO}$ promotes restoration of thrashing movement via induction of Daf-16 activation.

\subsection{Heat stress suppresses the activity of the insulin-like signaling pathway}

232 Daf-16 restored the thrashing movement in the WT strain (Figure 3). Additionally, 233 Daf-16 promoted restoration in the daf-2 mutant (Figure 4). Therefore, heat stress may affect the activity of the ILS pathway. To analyze the activity of the ILS pathway under heat stress, we measured gene expression of daf-28, a homolog of insulin, and ins-7, a homolog of IGF-1, which are Daf-2 agonists (Wormbase: http://www.wormbase.org). Therefore, we focused on their insulin-like peptides. The results showed that the ins-7 
and daf-28 expression was remarkably decreased by heat stress (Figure 5). Therefore, it was suggested that heat stress inactivates the insulin-like signaling pathway.

\section{Discussion}

We found that a novel function of Daf-16 was to restore the thrashing movement that was decreased by heat stress (Figure 3 and Figure 4). Daf-16 activity was enhanced immediately after heat treatment (Figure 2) and was suppressed by a daf-16 KO or RNAi, resulted in the increase of the stress resistance genes expression (Hsu et al., 2003; McColl et al., 2010). Therefore, enhancement of Daf-16 downstream genes is necessary for restoring the thrashing movement that was reduced by heat stress. Downstream genes of Daf-16, such as sod-3 and hsp-12.6, preserve cells from stress, including heat stress. In fact, it was reported that heat stress increased the fluorescent flux of DCF in C. elegans (Kampk"otter et al., 2007) and remarkably increased Sod-3 expression (Wolf et al., 2008). Research on poly-glutamine (PolyQ) diseases showed that knockdown of Daf-16 or Hsp-12.6 accelerated the aggregation of the PolyQ protein (Hsu et al., 2003) and daf-16 RNAi accelerated paralysis in a C. elegans of PolyQ disease model (Haldimann et al., 2011). And, hsp-12.6 expression was decreased due to restoration of thrashing movement in daf-2 mutant (Fig. 4A and Fig. 4C). Therefore, it is expected that Daf-16 activity possibly relate to removal of heat stress damage and restoration of the thrashing movement.

This restoration was promoted in a daf-2 $\mathrm{KO}$ in a daf-16-dependent manner (Figure 4). In the daf-2 mutant, Daf-16 is localized in the nucleus (Lin et al., 2001) and enhances the expression of stress resistance genes (Hsu et al., 2003; McElwee et al., 2003; Murphy et al., 2003). Therefore, it is expected that Daf-16 nuclear localization is maintained before and after heat shock in the daf-2 mutant. In other words, downstream genes of Daf-16 may be enhanced at all times in the daf- 2 mutant. In fact, hsp-12.6 level of daf-2 mutant was still high in recovery process compared to that of WT (Fig. 4C). Therefore, these results suggest that the consecutive activation of FoxO/Daf-16 accelerates heat stress damage recovery. However, daf-2 $\mathrm{KO}$ prevented the decline of thrashing movement in a Daf-16-independent manner (Fig. 4B). So, Daf-16 and its downstream genes are involved in restoration of thrashing movement only. Heat stress decreased daf-28 and ins-7 gene expression, agonists of Daf-2 (Figure 5). Our findings suggest that heat stress suppresses the activity of the ILS pathway. Daf-16 
272 is translocated to the nucleus from the cytoplasm by ins-7 RNAi (Murphy et al., 2007; 273 Kawli and Tan, 2008). It has also been shown that Daf-16 is localized in the nucleus by 274 daf-28 RNAi in the L2 larval stage (Li et al., 2003). Decreasing daf-28 and ins-7 275 promoted the C. elegans innate immunity against bacteria by Daf-16 (Kawli and Tan, 276 2008; Hahm et al., 2011). Additionally, the thrashing movement was restored via 277 Daf-16 in the daf-2 mutant (Figure 4). These findings strongly suggest that Daf-16 is 278 activated by heat stress via inactivation of the insulin-like signaling pathway.

279 FoxO families are the common transcription factor existed in wide varieties of 280 organisms, and have the similar functions on oxidative stress and longevity (Kenyon 281 2010). In fact, it is generally understood that FoxO increases expression of genes related 282 to anti-oxidant (Welker et al., 2013) in response to oxidative stress; Daf-16 increases 283 sod-3 expression under oxidative stress and promotes oxidative stress tolerance in $C$. 284 elegans (Honda and Honda, 1999; Yoshinaga et al., 2003). Furthermore, FoxO also 285 induces longevity in yeast (Postnikoff et al., 2012), C. elegans (Kenyon et al., 1993) and 286 D. melanogaster (Slack et al., 2011). In addition, it is reported that deletion of insulin 287 receptor extends lifespan in mice (Selman et al., 2008) and FoxO3a relates to longevity 288 in human too (Willcox et al., 2008; Anselmi et al., 2009; Flachsbart et al., 2009; Li et al., 289 2009; Kenyon 2010). Therefore, although the functions and the behaviors of FoxO 290 family under heat stress in other organisms are still unclear, it is expected that FoxO 291 families play the similar functions on thermotolerance in side varieties of species 292 including human. It was reported that keratinocyte-specific FoxO1 KO inhibits wound 293 healing in mice (Ponugoti et al., 2013). And, FoxO3a maintains the expression of 294 pro-autophagic genes and rescued the hematopoietic stem cells from apoptosis induced 295 by metabolic stress (Warr et al., 2013). Therefore, FoxO of mammals has, at least, the 296 function of removing and recovering damage. It is expected that our findings are 297 important for further analysis of thermotolerance and give the idea to establish the 298 treatment of heat stroke and summer weakness.

299 Overall, we concluded that FoxO/Daf-16 was activated by inhibiting the insulin-like 300 signaling pathway under heat stress, removed heat stress damage, and recovered 301 movement in $C$. elegans. In addition, we showed that consecutive activation of 302 FoxO/Daf-16 accelerated the heat stress damage recovery. Our findings not only 303 provide new knowledge of thermotolerance but also provide a strategy toward studying disorders related to heat stress, such as heat stroke and summer weakness.

306 Acknowledgments: This work was supported in part by Grants-in-Aid for Scientific 
Research from the Ministry of Education, Science, Sports, and Culture of Japan. We wish to thank Dr. A. Fire for providing the L4440 plasmid DNA. We also thank Dr. M. Fukuyama for providing worm TJ356. C. elegans strains were provided by the Caenorhabditis Genetics Center (MN, USA). We thank Dr. H. Miyazaki for supporting this work.

\section{References}

Alper, S., McBride, S.J., Lackford, B., Freedman, J.H., Schwartz, D.A., 2007. Specificity and Complexity of the Caenorhabditis elegans Innate Immune Response. Mol. Cell. Biol. 27, 5544-5553

Anselmi, C.V., Malovini, A., Roncarati, R., Novelli, V., Villa, F., Condorelli, G., Bellazzi, R., Puca, A.A., 2009. Association of the FOXO3A locus with extreme longevity in a southern Italian centenarian study. Rejuvenation Res. 12, 95-104

Bamps, S., Wirtz, J., Savory, F.R., Lake, D., Hope, I.A., 2009. The Caenorhabditis elegans sirtuin gene, sir-2.1, is widely expressed and induced upon caloric restriction. Mech Ageing Dev. 130, 762-770

Brenner. S., 1974. The genetics of Caenorhabditis elegans. Genetics. 77, 71-96

Flachsbart, F., Caliebe, A., Kleindorp, R., Blanché, H., von Eller-Eberstein, H., Nikolaus, S., Schreiber, S., Nebel, A., 2009. Association of FOXO3A variation with human longevity confirmed in German centenarians. Proc. Natl Acad. Sci. USA 106, 2700-2705

Hahm, J.H., Kim, S., Paik, Y.K., 2011. GPA-9 is novel regulator of innate immunity against Escherichia coli foods in adult Caenorhabditis elegans. Aging Cell. 10, 208-219

Haldimann, P., Muriset, M., Vigh, L., Goloubinoff, P., 2011. The Novel Hydroxylamine Derivative NG-094 Suppresses Polyglutamine Protein Toxicity in Caenorhabditis elegans. J. Biol. Chem. 286, 18784-18794

Hashimoto, T., Horikawa, M., Nomura, T., Sakamoto, K., 2010. Nicotinamide adenine dinucleotide extends the lifespan of Caenorhabditis elegans mediated by sir- 2.1 and daf-16. Biogerontology. 11, 31-43

Heidler, T., Hartwig, K., Daniel, H., Wenzel, U., 2010. Caenorhabditis elegans lifespan extension caused by treatment with an orally active ROS-generator is dependent on DAF-16 and SIR-2.1. Biogerontology. 11, 183-195 
Henderson, S.T., Johnson, T.E., 2001. daf-16 integrates developmental and environmental inputs to mediate aging in the nematode Caenorhabditis elegans. Curr. Biol. 11, 1975-1980

Honda, Y., Honda, S., 1999. The daf-2 gene network for longevity regulates oxidative stress resistance and Mn-superoxide dismutase gene expression in Caenorhabditis elegans. FASEB. J. 13, 1385-1393

Horikawa, M., Sakamoto, K., 2009. Fatty-acid metabolism is involved in stress-resistance mechanisms of Caenorhabditis elegans. Biochem. Biophys. Res. Commun. 390, 1402-1407

Horikawa, M., Sakamoto, K., 2010. Polyunsaturated fatty acids are involved in regulatory mechanism of fatty acid homeostasis via daf-2/insulin signaling in Caenorhabditis elegans. Mol. Cell. Endocrinol. 323, 183-192

Hsu, A.L., Murphy, C.T., Kenyon, C., 2003. Regulation of Aging and Age-Related Disease by DAF-16 and Heat-Shock Factor. Science. 300, 1142-1145

Jones, D., Candido, E.P., 1999. Feeding Is Inhibited by Sublethal Concentrations of Toxicants and by Heat Stress in the Nematode Caenorhabditis elegans: Relationship to the Cellular Stress Response. J. Exp. Zool. 284, 147-157

Kampinga, H.H., 1993. Thermotolerance in mammalian cells. J. Cell. Sci. 104, 11-17

Kampk"otter, A., Nkwonkam, C.G., Zurawski, R.F., Timpel, C., Chovolou, Y., W“atjen, W., Kahl, R., 2007. Investigations of protective effects of the flavonoids quercetin and rutin on stress resistance in the model. Toxicology. 234, 113-123

Kawli, T., Tan, M.W., 2008. Neuroendocrine signals modulate the innate immunity of Caenorhabditis elegans through insulin signaling. Nat. Imm. 9, 1415-1424

Kenyon, C., Chang, J., Gensh, E., Rudner, A., Tabtlang, R., 1993. A C. elegans mutant that lives twice as long as wild type. Nature. 366, 461-464

Kenyon, C.J., 2010. The genetics of aging. Nature. 464, 504-512

Kourtis, N., Nikoletopoulou, V., Tavernarakis, N., 2012. Small heat-shock proteins protect from heat-stroke-associated neurodegeneration. Nature. 490, 213-218

Kwon, E.S., Narasimhan, S.D., Yen, K., Tissenbaum, H.A., 2010. A new DAF-16 isoform regulates longevity. Nature. 466, 498-502

Lanner, J.T., Georgiou, D.K., Dagnino-Acosta, A., Ainbinder, A., Cheng, Q., Joshi, A.D., Chen, Z., Yarotskyy, V., Oakes, J.M., Lee, C., Monroe, T.O., Santillan, A., Dong, K., Goodyear, L., Ismailow, I., Rondney, G.G., Dirksen, R.T., Hamilton, S.L., 2012. AICAR prevents heat-induced sudden death in RyR1 mutant mice 
independent of AMPK activation. Nat. Med. 18, 244-251

Li, W., Kennedy, S.G., Ruvkun, G., 2003. daf-28 encodes a C. elegans insulin superfamily member that is regulated by environmental cues and acts in the DAF-2 signaling pathway. Genes. Dev. 17, 844-858

Li, Y., Wang, W.J., Cao, H., Lu, J., Wu, C., Hu, F.Y., Guo, J., Zhao, L., Yang, F., Zhang, Y.X., Li, W., Zheng, G.Y., Cui, H., Chen, X., Zhu, Z., He, H., Dong, B., Mo, X., Zeng, Y., Tian, X.L., 2009. Genetic association of FOXO1A and FOXO3A with longevity trait in Han Chinese populations. Hum. Mol. Genet. 18, 4897-4904

Lin, K., Hsin, H., Libina, N., Kenyon, C., 2001. Regulation of the Caenorhabditis elegans longevity protein DAF-16 by insulin/IGF-1 and germline signaling. Nat. Genet. 28, 139-145

Lithgow, G.J., White, T.M., Melov, S., Johnson, T.E., 1995. Thermotolerance and extended life-span conferred by single-gene mutations and induced by thermal stress. Proc. Natl. Acad. Sci. USA. 92, 7540-7544

McColl, G., Rogers, A.N., Alavez, S., Hubbard, A.E., Melov, S., Link, C.D., Bush, A.I., Kapahi, P., Lithgow, G.J., 2010. Insulin-like Signaling Determines Survival during Stress via Posttranscriptional Mechanisms in C. elegans. Cell. Metab. 12, 260-272

McElwee, J., Bubb, K., Thomas, J.H., 2003. Transcriptional outputs of the Caenorhabditis elegans forkhead protein DAF-16. Aging Cell. 2, 111-121

Morley, J.F., Brignull, H.R., Weyers, J.J., Morimoto, R.I., 2002. The threshold for polyglutamine-expansion protein aggregation and cellular toxicity is dynamic and influenced by aging in Caenorhabditis elegans. Proc. Natl. Acad. Sci. USA. 99, $10417-10422$

Murphy, C.T., McCarroll, A., Bargmann, C.I., Fraser, A., Kamath, R.S., Ahringer, J., Li, H., Kenyon, C., 2003. Genes that act downstream of DAF-16 to influence the lifespan of Caenorhabditis elegans. Nature. 424, 277-283

Murphy, C.T., Lee, S.J., Kenyon, C., 2007. Tissue entrainment by feedback regulation of insulin gene expression in the endoderm of Caenorhabditis elegans. Proc. Natl. Acad. Sci. USA. 104, 19046-19050

Ponugoti, B., Xu, F., Zhang, C., Tian, C., Pacios, S., Graves, D.T., 2013. FOXO1 promotes wound healing through the up-regulation of TGF- $\beta 1$ and prevention of oxidative stress. J. Cell. Biol. 203, 327-43

Postnikoff, S.D., Malo, M.E., Wong, B., Harkness, T.A., 2012. The yeast forkhead 
transcription factors fkh1 and fkh2 regulate lifespan and stress response together with the anaphase-promoting complex. PLoS Genet. 8, e1002583

Selman, C., Lingard, S., Choudhury, A.I., Batterham, R.L., Claret, M., Clements, M., Ramadani, F., Okkenhaug, K., Schuster, E., Blanc, E., Piper, M.D., Al-Qassab, H., Speakman, J.R., Carmignac, D., Robinson, I.C., Thornton, J.M., Gems, D., Partridge, L., Withers, D.J., 2008. Evidence for lifespan extension and delayed age-related biomarkers in insulin receptor substrate 1 null mice. FASEB. J. 22, $807-818$

Singh, V., Aballay, A., 2006. Heat-shock transcription factor (HSF)-1 pathway required for Caenorhabditis elegans immunity. Proc. Natl. Acad. Sci. USA. 103, 13092-13097

Singh, V., Aballay, A., 2009. Regulation of DAF-16-mediated Innate Immunity in Caenorhabditis elegans. J. Biol. Chem. 284, 35580-35587

Slack, C., Giannakou, M.E., Foley, A., Goss, M., Partridge, L., 2011. dFOXO-independent effects of reduced insulin-like signaling in Drosophila. Aging Cell. 10, 735-48

Timmons, L., Fire, A., 1998. Specific interference by ingested dsRNA. Nature. 395, 854 van Ham, T.J., Holmberg, M.A., van der Goot, A.T., Teuling, E., Garcia-Arencibia, M., Kim, H.E., Du, D., Thijssen, K.L., Wiersma, M., Burggraaff, R., van Bergeijk, P., van Rheenen, J., Jerre van Veluw, G., Hofstra, R.M., Rubinsztein, D.C., Nollen, E.A., 2010. Identification of MOAG-4/SERF as a Regulator of Age-Related Proteotoxicity. Cell. 142, 601-612

Warr, M.R., Binnewies, M., Flach, J., Reynaud, D., Garg, T., Malhotra, R., Debnath, J., Passegue, E., 2013. FOXO3A directs a protective autophagy program in haematopoetic stem cells. Nature. 494, 323-327

Weinkove, D., Halstead, J.R., Gems, D., Divecha, N., 2006. Long-term starvation and ageing induce AGE-1/PI3-kinase-dependent translocation of DAF-16/FOXO to the cytoplasm. BMC. Biol. 4, 1

Welker, A.F., Moreira, D.C., Campos, É.G., Hermes-Lima, M., 2013. Role of redox metabolism for adaptation of aquatic animals to drastic changes in oxygen availability. Comp. Biochem. Physiol. A. 165, 384-404

Willcox, B.J., Donlon, T.A., He, Q., Chen, R., Grove, J.S., Yano, K., Masaki, K.H., Willcox, D.C., Rodriguez, B., Curb, J.D., 2008. FOXO3A genotype is strongly associated with human longevity. Proc. Natl Acad. Sci. USA 105, 13987-13992 
Wolf, M., Nunes, F., Henkel, A., Heinick, A., Paul, R.J., 2008. The MAP Kinase JNK-1 of Caenorhabditis elegans: Location, Activation, and Influences Over Temperature-Dependent Insulin-Like Signaling, Stress Responses, and Fitness. J. Cell. Physiol. 214, 721-729

Yen, K., Narasimhan, S.D., Tissenbaum, H.A., 2011. DAF-16/Forkhead box O transcription factor: many paths to a single Fork(head) in the road. Antioxid. Redox. Signal. 14, 623-634

Yoshinaga, T., Kaneko, G., Kinoshita, S., Tsukamoto, K., Watabe, S., 2003. The molecular mechanisms of life history alterations in a rotifer: a novel approach in population dynamics. Comp. Biochem. Physiol. B. 136, 715-722

\section{Legends}

Figure 1. Alteration of movement under heat stress. (A) An age-synchronized L1 larva was transferred to an NGM plate seeded with OP50 and cultured for 4 days at $20^{\circ} \mathrm{C}$. Adult worms were transferred to a new NGM plate seeded with OP50 and cultured at $35^{\circ} \mathrm{C}$ for $0-4 \mathrm{~h}$. Ten $C$. elegans were chosen randomly and pumping was counted for $15 \mathrm{~s}$ every h. 3 independent experiments were performed and these data were combined for graph. Significant differences were analyzed with t-test. $\mathrm{N}=30$, mean $\pm \mathrm{SE},{ }^{*} P<0.05, * * P<0.005$. (B) An age-synchronized L1 larva was transferred to an NGM plate seeded with OP50 and cultured for 4 days at $20^{\circ} \mathrm{C}$. Adult worms were transferred to an NGM plate seeded with OP50 (+) or an E. coli-free NGM plate (-) and cultured for $4 \mathrm{~h}$ at $20^{\circ} \mathrm{C}$ or $35^{\circ} \mathrm{C}$. After $4 \mathrm{~h}$, C. elegans was transferred to a new NGM plate seeded with OP50 and cultured for 0-24 h. After 0-24 h, 10 C. elegans chosen randomly were transferred to S-basal on E. coli-free NGM plates. Thrashing movement was counted for 15 s. 3 independent experiments were performed and these data were combined for graph. Significant differences were analyzed with t-test. $N=30$, mean \pm $\mathrm{SE}, * P<0.05, * * P<0.005$.

Figure 2. Activity of Daf-16 under heat stress. (A) An age-synchronized L1 larva of TJ356 was transferred to an NGM plate seeded with OP50 and cultured for 4 days at $20^{\circ} \mathrm{C}$. Adult worms were transferred to an NGM plate seeded with OP50 (+) or an $E$. coli-free NGM plate (-) and cultured for $4 \mathrm{~h}$ at $20^{\circ} \mathrm{C}$ or $35^{\circ} \mathrm{C}$. TJ356 cultured in each 
condition were transferred to new NGM plates seeded with OP50. TJ356 were fixed in $1 \%$ PFA solution. Fluorescence emitted by GFP was observed using fluorescence microscopy. The number of worms that GFP was localized in the nucleus (Nuc), cytosol (Cyto) or both of them was counted. 3 independent experiments were performed and these data were combined for making graph. $N=3$, mean $\pm \mathrm{SE}$, Scale $=100 \mu \mathrm{m}$. (B) An age-synchronized L1 larva was transferred to an NGM plate seeded with OP50 and cultured for 4 days at $20^{\circ} \mathrm{C}$. Adult worms were transferred to an NGM plate seeded with OP50 (+) or an E. coli-free NGM plate (-) and cultured for $4 \mathrm{~h}$ at $20^{\circ} \mathrm{C}$ or $35^{\circ} \mathrm{C}$. RNA was extracted and cDNA was synthesized. Expression of hsp-12.6 was measured using qRT-PCR. 2 independent experiments were performed and these data were combined for graph. In each trial, gene expression was analyzed by 3 different wells. Significant differences were analyzed with Dunnett's T3 test. $\mathrm{N}=6$, mean $\pm \mathrm{SE},{ }^{*} P<0.05, * * P<$ 0.005 .

\section{Figure 3. Alteration of thrashing movement by Daf-16 KO under heat stress.} (A) An age-synchronized L1 larva was transferred to an NGM plate seeded with OP50 and cultured for 4 days at $20^{\circ} \mathrm{C}$. Adult worms were transferred to an E. coli-free NGM plate and cultured for $4 \mathrm{~h}$ at $20^{\circ} \mathrm{C}$ or $35^{\circ} \mathrm{C}$. After $4 \mathrm{~h}$, C. elegans were transferred to a new NGM plate seeded with OP50 and cultured for 0-24 h. After 0, 12, or 24 h, $10 C$. elegans chosen randomly were transferred to S-basal on E. coli-free NGM plates. Thrashing movement was counted for $15 \mathrm{~s}$. The graph shows the movement of $C$. elegans treated by heat stress divided by the movement of $C$. elegans untreated by heat stress. 3 independent experiments were performed and these data were combined graph. Significant differences were analyzed with t-test. $\mathrm{N}=30$, mean $\pm \mathrm{SE}, * P<0.05, * * P<$ 0.005. Details are shown in Table 2. (B) An age-synchronized L1 larva was transferred to an RNAi plate and cultured for 4 days at $20^{\circ} \mathrm{C}$. Adult worms were transferred to an $E$. coli-free NGM plate and cultured for $4 \mathrm{~h}$ at $20^{\circ} \mathrm{C}$ or $35^{\circ} \mathrm{C}$. After $4 \mathrm{~h}$, C. elegans were transferred to a new NGM RNAi media plate cultured for 0-24 h. After 0, 12, or $24 \mathrm{~h}$, 10 C. elegans chosen randomly were transferred to S-basal on E. coli-free NGM plates. Thrashing movement was counted for 15 s. C. elegans treated by heat stress divided by movement of $C$. elegans untreated by heat stress. 3 independent experiments were performed and these data were combined for graph. Significant differences were analyzed with t-test. $\mathrm{N}=30$, mean $\pm \mathrm{SE}, * P<0.05,{ }^{*} * P<0.005$. Details are shown in Table 2. (C) An age-synchronized L1 larva of TJ356 was transferred to an RNAi plate 
510 and cultured for 4 days at $20^{\circ} \mathrm{C}$. Adult worms were fixed in $1 \%$ PFA solution, and

511 fluorescence was observed via fluorescence microscopy. Scale $=100 \mu \mathrm{m}$.

513 Figure 4. Alteration of thrashing movement by Daf-2 KO under heat stress. (A)

514 An age-synchronized L1 larva was transferred to an NGM plate seeded with OP50 and 515 cultured for 4 days at $20^{\circ} \mathrm{C}$. Adult worms were transferred to an E. coli-free NGM plate 516 and cultured for $4 \mathrm{~h}$ at $20^{\circ} \mathrm{C}$ or $35^{\circ} \mathrm{C}$. After $4 \mathrm{~h}$, C. elegans were transferred to a new 517 NGM plate seeded with OP50 and cultured for 0-6 h. After 0, 3, or 6 h, 10 C. elegans 518 chosen randomly were transferred to S-basal on E. coli-free NGM plates. Thrashing 519 movement was counted for $15 \mathrm{~s}$. The graph shows the movement of C. elegans treated 520 by heat stress divided by the movement of $C$. elegans untreated by heat stress. 3 521 independent experiments were performed and these data were combined for graph. 522 Significant differences were analyzed with t-test. $\mathrm{N}=30$, mean $\pm \mathrm{SE}, * P<0.05$, $* * P<$ 523 0.005. Details are shown in Table 3. (B) An age-synchronized L1 larva was transferred 524 to an RNAi plate and cultured for 4 days at $20^{\circ} \mathrm{C}$. Adult worms were transferred to an $E$. 525 coli-free NGM plate and cultured for $4 \mathrm{~h}$ at $20^{\circ} \mathrm{C}$ or $35^{\circ} \mathrm{C}$. After $4 \mathrm{~h}$, C. elegans were 526 transferred to a new NGM RNAi media plate cultured for $0-6 \mathrm{~h}$. After 0,3 , or $6 \mathrm{~h}, 10 C$. 527 elegans chosen randomly were transferred to S-basal on E. coli-free NGM plates. 528 Thrashing movement was counted for $15 \mathrm{~s}$. The graph shows the movement of $C$. 529 elegans treated by heat stress divided by the movement of $C$. elegans untreated by heat 530 stress. 3 independent experiments were performed and these data were combined for 531 graph. Significant differences were analyzed with Games-Howell test. $\mathrm{N}=30$, mean \pm $532 \mathrm{SE}, * P<0.05,{ }^{*} P<0.005$. Details are shown in Table 3. (C) An age-synchronized L1 533 larva was transferred to an NGM plate seeded with OP50 and cultured for 4 days at $53420^{\circ} \mathrm{C}$. Adult worms were transferred to an E. coli-free NGM plate and cultured for $4 \mathrm{~h}$ at $53535^{\circ} \mathrm{C}$. After $4 \mathrm{~h}$, RNA was extracted from $C$. elegans as $0 \mathrm{~h}$ or $C$. elegans were 536 transferred to a new NGM plate seeded with OP50 and cultured for 3-6h. After 3 or $6 \mathrm{~h}$, 537 RNA was extracted from C. elegans. cDNA was synthesized and expression of hsp-12.6 538 was measured by qRT-PCR. Gene expression was analyzed by 3 different wells. 539 Significant differences were analyzed with t-test. $\mathrm{N}=6$, mean $\pm \mathrm{SE}, * P<0.05$, $* * P<$ $540 \quad 0.005$.

543 Figure 5. Activity of insulin-like signaling pathway under heat stress. An 
544 age-synchronized L1 larva was transferred to an NGM plate seeded with OP50 and 545 cultured for 4 days at $20^{\circ} \mathrm{C}$. Adult worms were transferred to an NGM plate seeded with 546 OP50 (+) or an E. coli-free NGM plate (-) and cultured for $4 \mathrm{~h}$ at $20^{\circ} \mathrm{C}$ or $35^{\circ} \mathrm{C}$. RNA 547 was extracted and cDNA was synthesized. Expression of daf-28 and ins-7 was 548 measured by using qRT-PCR. 2 independent experiments were performed and these 549 data were combined for graph. In each trial, gene expression was analyzed by 3 550 different wells. Significant differences were analyzed with Dunnett's T3 test. $\mathrm{N}=6$, 551 mean $\pm \mathrm{SE}, * P<0.05, * * P<0.005$. 
Table 1. Primer sequences for quantitative PCR.

\begin{tabular}{lllc}
\hline Gene & Sense & Antisense & Reference \\
\hline (qRT-PCR) & & & \\
Pan-actin* & TCGGTATGGGACAGA & CATCCCAGTTGGTGACG & Kawli and \\
& AGGAC & ATA & Tan, 2008 \\
hsp-12.6 & TGGAGTTGTCAATGT & GACTTCAATCTCTTTTGG & Kwon et \\
& CCTCG & GAGG & al., 2010 \\
ins-7 & CATGCGAATCGAATA & GAAGTCGTCGGTGCATT & Kawli and \\
& CTGAAG & C & Tan, 2008 \\
daf-28 & TTCCGTATGTGTGGA & TTTGTATATACTCGGCA & Hahm et \\
& GTGTC & GTGC & al., 2011 \\
\hline \hline \multirow{2}{*}{ RNAi) } & & & Hashimoto \\
daf-16 & CATGGATCCATCCAG & CATGGATCCGTATGCTG & et al., 2010 \\
\hline
\end{tabular}


Table 2. Times of thrashing movement in Figure 3.

\begin{tabular}{lcccccccc}
\hline Strain & Time $(\mathrm{hr})$ & $\mathrm{N}$ & $20^{\circ} \mathrm{C}(\mathrm{mean} \pm \mathrm{SEM})$ & \multicolumn{3}{c}{$35^{\circ} \mathrm{C}(\mathrm{mean} \pm \mathrm{SEM})$} \\
\hline wild type & 0 & 30 & 55.17 & \pm & 1.44 & 1.57 & \pm & 0.36 \\
& 12 & 30 & 50.30 & \pm & 1.10 & 26.67 & \pm & 2.55 \\
& 24 & 30 & 42.27 & \pm & 1.00 & 32.63 & \pm & 2.10 \\
daf-16 (mgDf50) & 0 & 30 & 63.63 & \pm & 1.75 & 2.70 & \pm & 1.05 \\
& 12 & 30 & 56.07 & \pm & 1.86 & 13.20 & \pm & 2.10 \\
& 24 & 30 & 55.67 & \pm & 1.19 & 11.13 & \pm & 2.54 \\
\hline \hline \multirow{2}{*}{ empty vector } & 0 & 30 & 49.87 & \pm & 1.06 & 6.83 & \pm & 1.41 \\
& 12 & 30 & 49.07 & \pm & 1.31 & 40.07 & \pm & 1.39 \\
& 24 & 30 & 43.03 & \pm & 1.34 & 38.53 & \pm & 1.34 \\
daf-16 RNAi & 0 & 30 & 47.30 & \pm & 1.27 & 6.33 & \pm & 1.30 \\
& 12 & 30 & 50.27 & \pm & 1.77 & 25.47 & \pm & 2.31 \\
& 24 & 30 & 44.47 & \pm & 1.27 & 27.90 & \pm & 1.53 \\
\hline
\end{tabular}

603

604

605

606

607

608

609

610

611

612

613

614

615

616

617

618

619

These values show times of thrashing movement in Figure 3. $\mathrm{N}$ shows the number of $C$. elegans at each temperature. 
Table 3. Times of thrashing movement in Figure 4.

\begin{tabular}{|c|c|c|c|c|c|c|c|c|}
\hline \multirow{2}{*}{$\begin{array}{l}\text { Strain } \\
\text { Wild type }\end{array}$} & \multirow{2}{*}{$\begin{array}{c}\text { Time } \\
(\mathrm{hr})\end{array}$} & \multirow{2}{*}{$\frac{N}{30}$} & \multicolumn{3}{|c|}{$20^{\circ} \mathrm{C}($ mean $\pm \mathrm{SEM})$} & \multicolumn{3}{|c|}{$35^{\circ} \mathrm{C}($ mean $\pm \mathrm{SEM})$} \\
\hline & & & 53.20 & \pm & 1.14 & 3.43 & \pm & 0.88 \\
\hline & 3 & 30 & 55.10 & \pm & 1.42 & 11.60 & \pm & 1.49 \\
\hline & 6 & 30 & 45.67 & \pm & 1.06 & 13.87 & \pm & 1.88 \\
\hline \multirow[t]{3}{*}{ daf-2 (e1370) } & 0 & 30 & 63.97 & \pm & 0.84 & 21.60 & \pm & 2.36 \\
\hline & 3 & 30 & 58.13 & \pm & 0.98 & 45.07 & \pm & 1.58 \\
\hline & 6 & 30 & 53.23 & \pm & 1.17 & 49.07 & \pm & 1.52 \\
\hline \multirow[t]{3}{*}{ Wild type + empty } & 0 & 30 & 56.37 & \pm & 1.01 & 10.20 & \pm & 2.26 \\
\hline & 3 & 30 & 49.50 & \pm & 1.03 & 15.73 & \pm & 1.67 \\
\hline & 6 & 30 & 52.07 & \pm & 1.31 & 28.20 & \pm & 2.55 \\
\hline \multirow[t]{3}{*}{ daf-2 + empty } & 0 & 30 & 62.90 & \pm & 1.25 & 40.53 & \pm & 1.99 \\
\hline & 3 & 30 & 61.40 & \pm & 1.04 & 59.37 & \pm & 1.85 \\
\hline & 6 & 30 & 61.43 & \pm & 1.41 & 63.20 & \pm & 1.45 \\
\hline \multirow[t]{3}{*}{ daf-2 + daf-16 RNAi } & 0 & 30 & 61.60 & \pm & 1.40 & 33.90 & \pm & 2.07 \\
\hline & 3 & 30 & 56.20 & \pm & 1.04 & 33.60 & \pm & 1.32 \\
\hline & 6 & 30 & 54.87 & \pm & 1.01 & 39.27 & \pm & 2.10 \\
\hline
\end{tabular}

These values show times of thrashing movement in Figure 4 . N shows the number of $C$.

625 elegans at each temperature.

626

627

628

629

630

631

632

633

634

635 

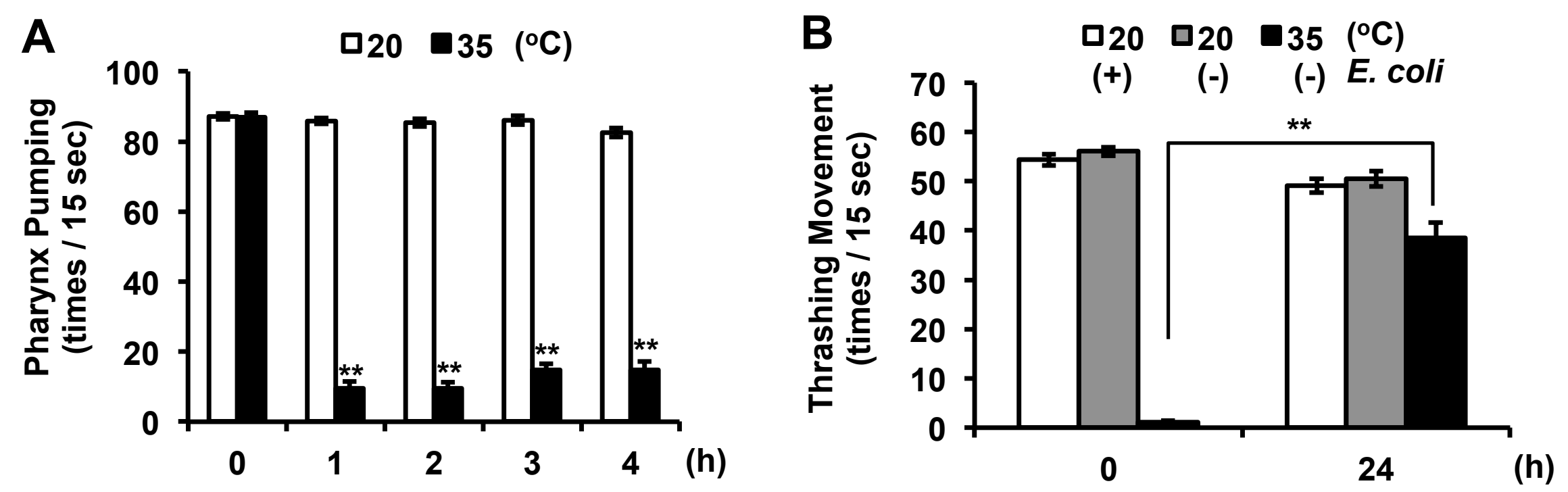

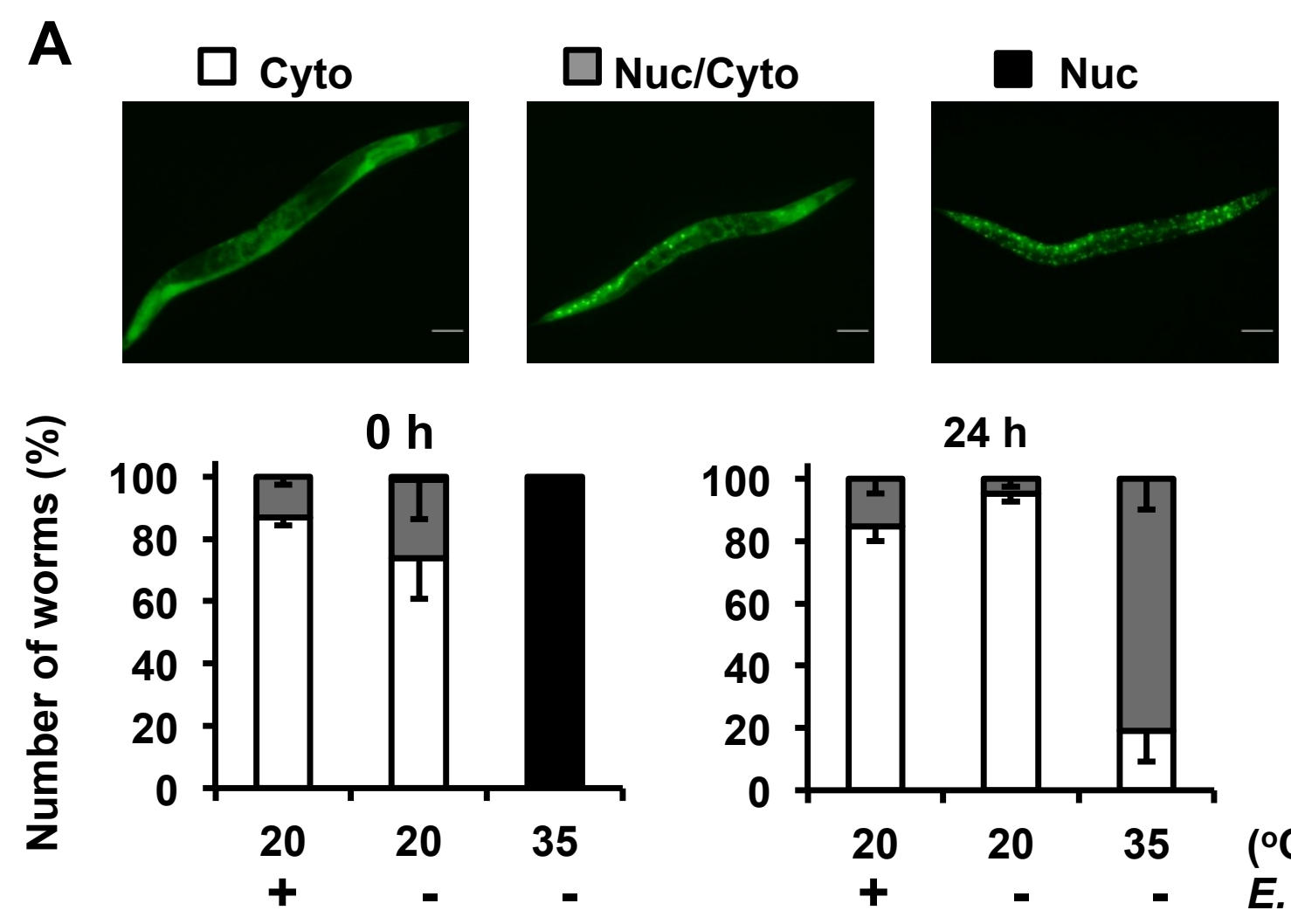

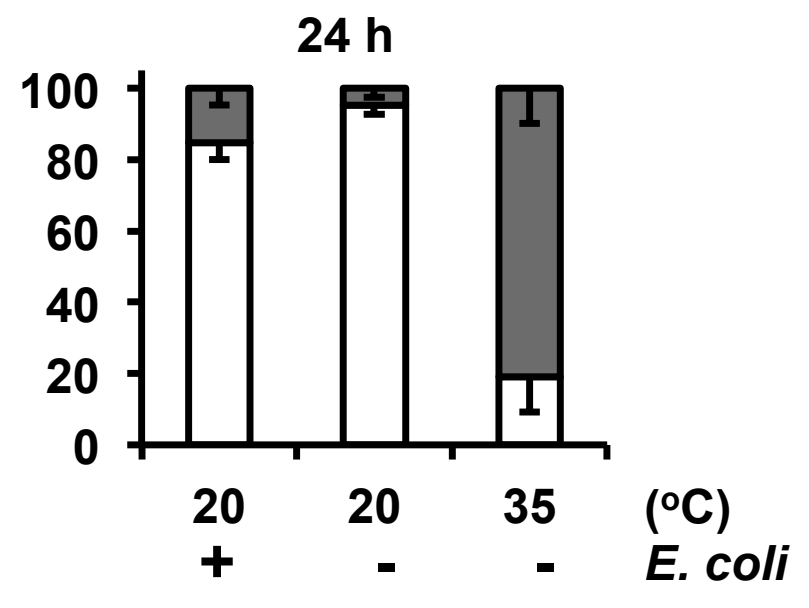

B

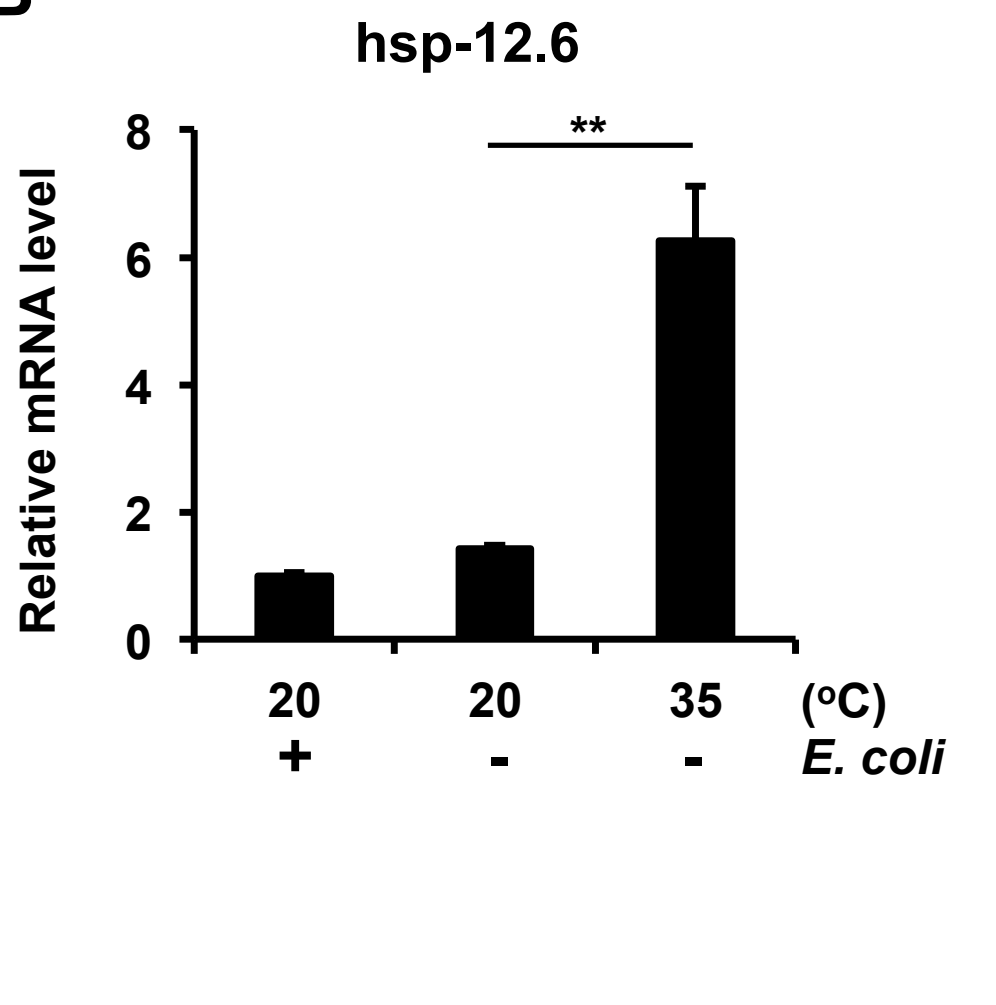



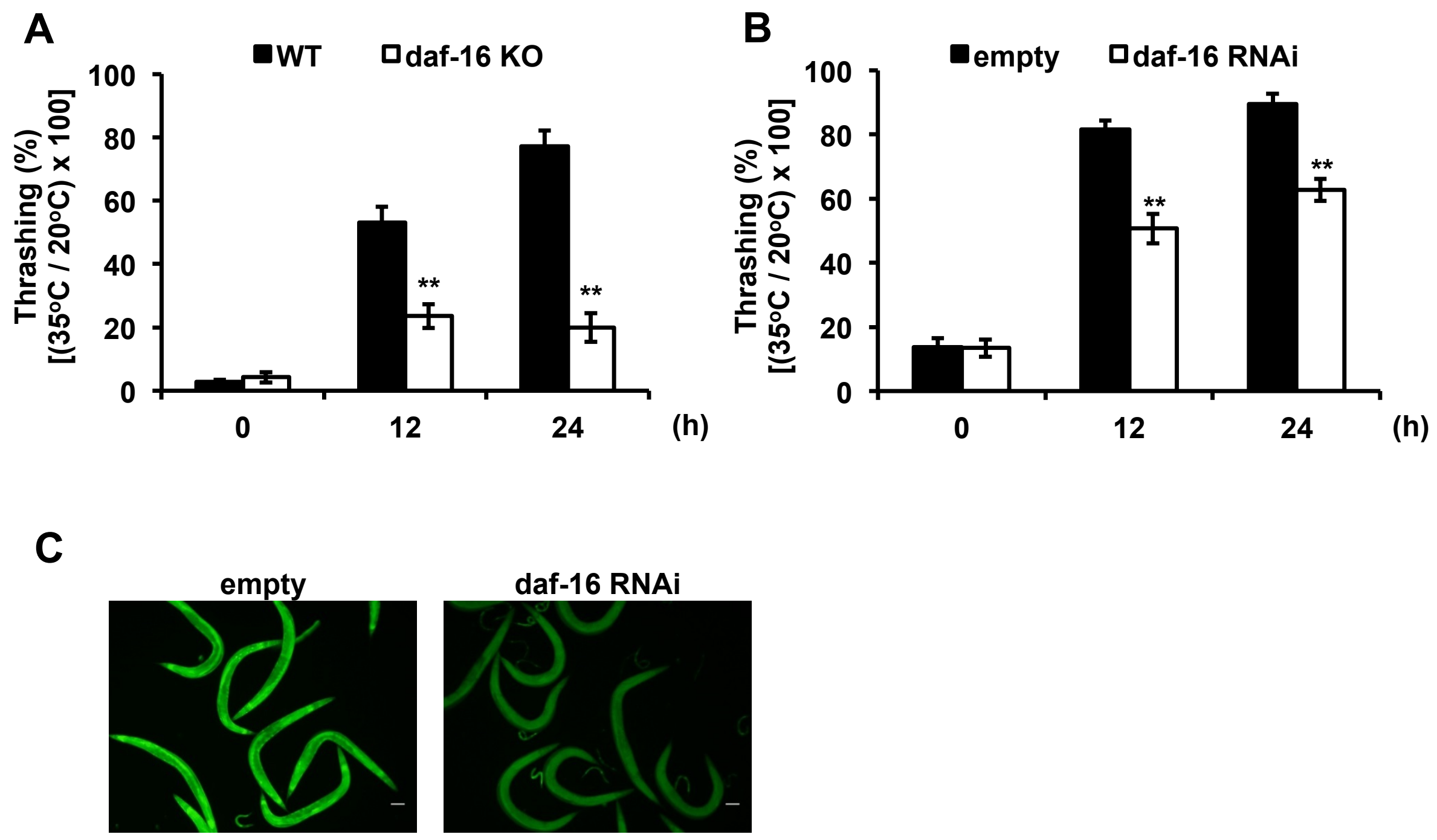
A

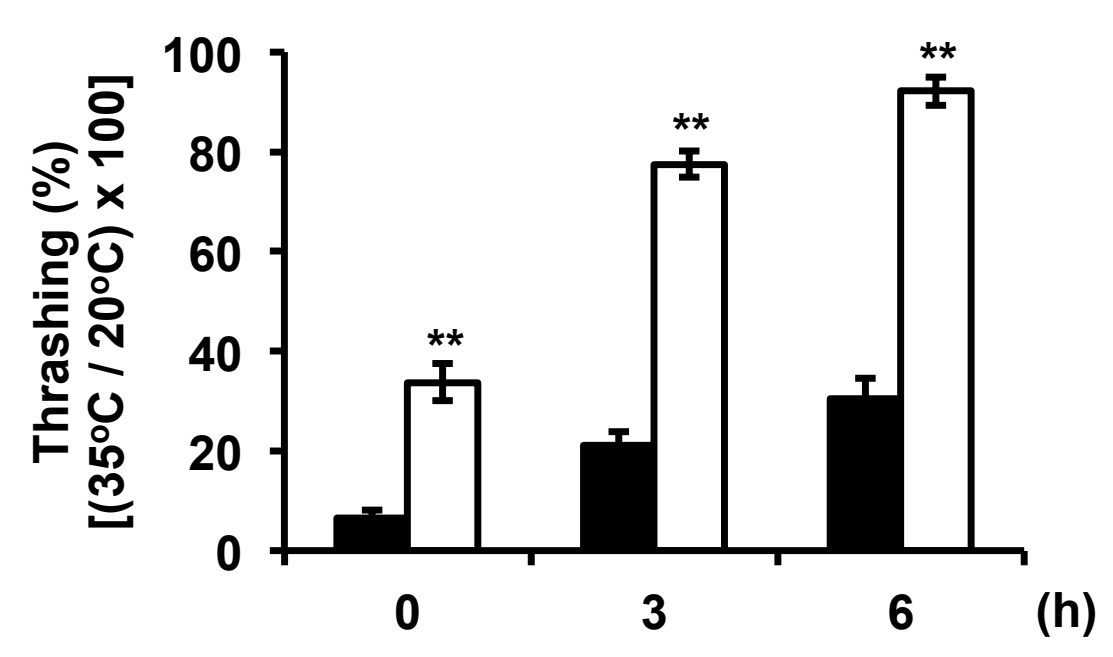

B

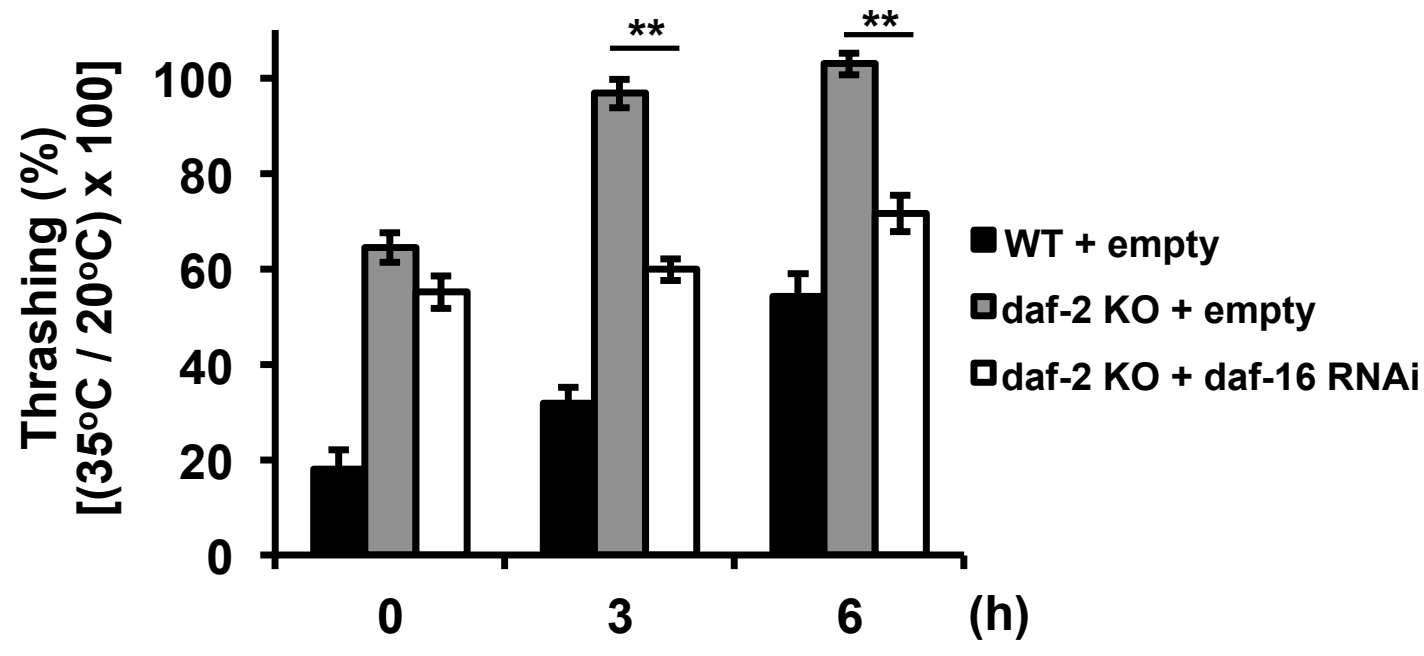

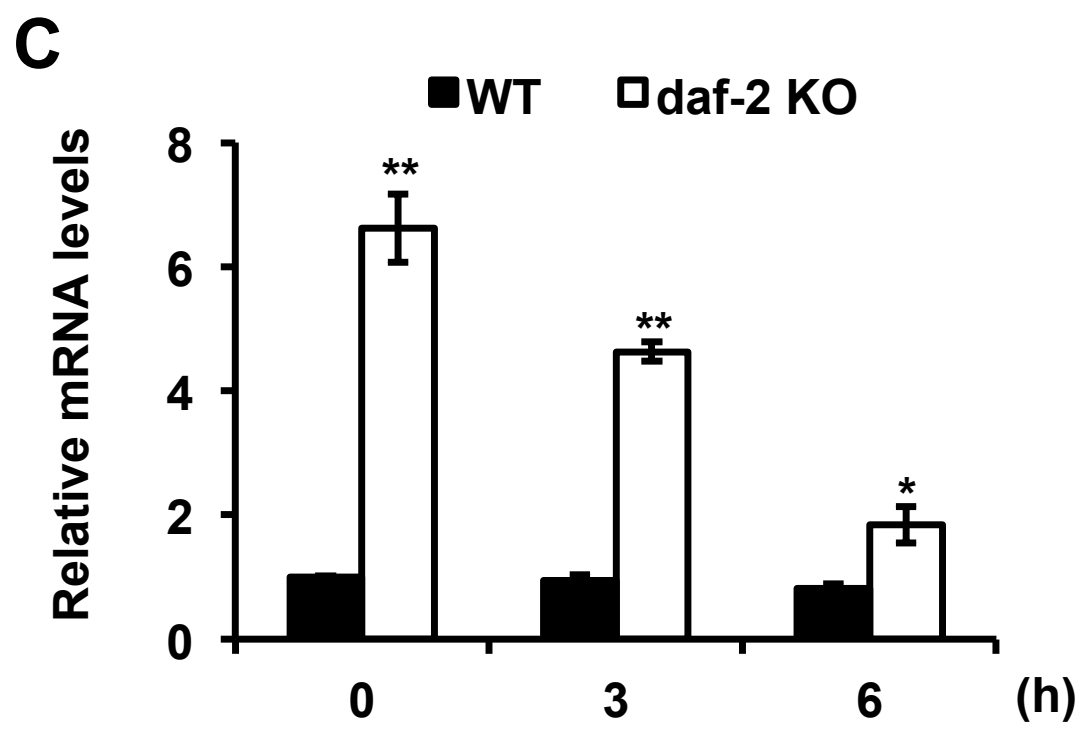




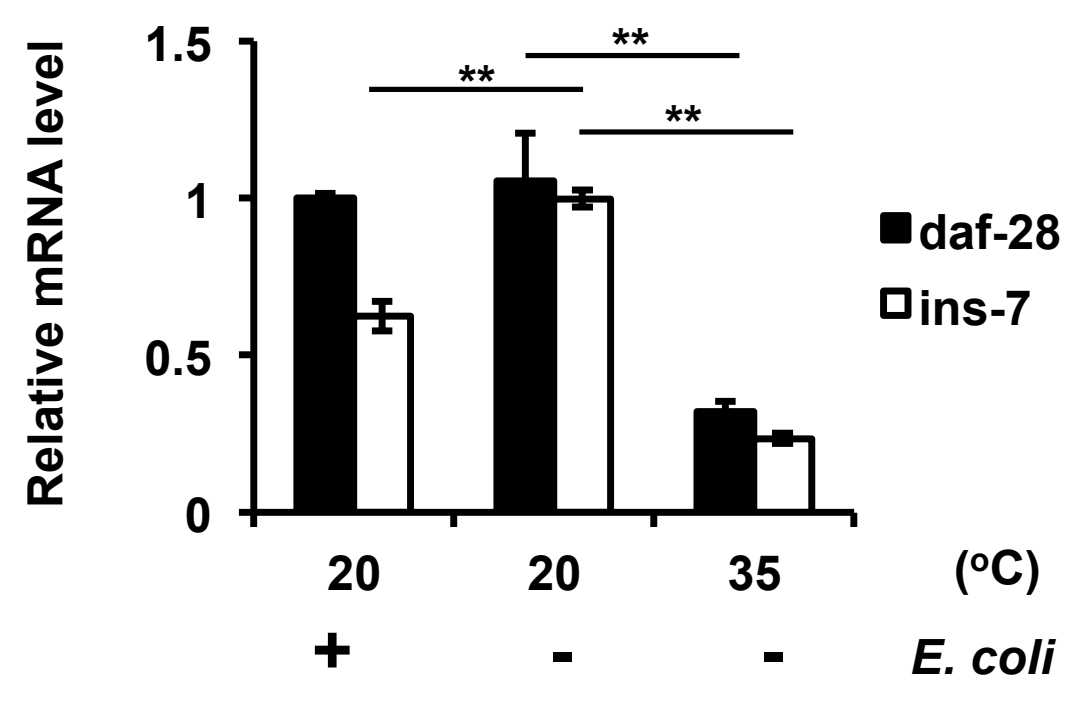

